\title{
MISSION CRITICAL COMPUTER RESOURCES MANAGEMENT GUIDE
}

DEFENSE SYSTEMS MANAGEMENT COLLEGE

FT. BELVOIR, VA 22060-5426 For sale by the Superindtendent of Documents, U. S. Government Printing Office
Washington, D.C. 20402 